Проанализировав все вышесказанное, можно заметить, что многое делано, но часто таким интерьерам не достает художественной выразительности, а в некоторых случаях вообще нет специализированныхпомещений для детского развития.

Внутреннее пространство должно воспроизводить космический образ жизни, всем известный по различным мультфильмам и фильмам, а так же данные музеи должны носить образовательный характер. Формы должны быть,по возможности, обтекаемыми.

Помещение, где находятся дети может быть ярким, этого можно добиться благодаря контрасту некоторых цветов, например, синего и желтого. Напольное покрытие может быть разным, как однотонным: либо темным, либопочти белым, серебристо-металлизированным, так и стилизованным. Освещение - соответствовать общему стилевому решению (светодиодное, точечное). Такие параметры сразу вызывают космические ассоциации, но самоеглавное - чтобы ребенку было комфортно и тянуло к познанию космической темы.

1. http://dkgagarina34.ru

2. http://www.tpark.ru/June/First.html

3. https://dkc43.ru

4. http://www.kosmo-museum.ru

5. https://www.admagazine.ru/interior/17-luchshih-futuristicheskih-filmov

6. https://worldscholarshipforum.com/ru/лучшие-аэрокосмические-инженерные-школы/

7. https://dkc43.ru/?page_id=357

\title{
Михайлова Г.И. \\ Эффективность метода проектов в обучении иностранному языку в вузе
}

Новосибирский государственный архитектурно-строительный университет (Россия, Новосибирск)

doi: 10.18411/trnio-01-2022-145

\section{Аннотация}

В статье анализируется метод проектов в обучении иностранному языку в неязыковом вузе. Данный метод служит своего рода катализатором интереса обучаемых к предмету, поскольку предоставляет возможность творческого подхода в рамках языковой деятельности, апеллирует к самостоятельной работе с иноязычной информацией при реализации проекта, учит командной работе в достижении общей цели.

Ключевые слова: метод проектов, эффективность, мотивация, иностранный язык, речевая деятельность, роль ментора, неязыковой вуз.

\section{Abstract}

The article analyzes the method of projects in teaching a foreign language in a non-linguistic higher school. This method serves as a kind of catalyst for students' interest in the subject, since it provides an opportunity for a creative approach within the framework of language activities, appeals to independent work with foreign language information during the implementation of a project, teaches to work as a team in achieving a common goal.

Keywords: method of projects, effectiveness, motivation, foreign language, speech activity, mentor work, non-linguistic higher school.

Выбор темы обусловлен, с одной стороны, ее актуальностью, с другой стороны, не полной освещенностью данной проблемы в отношении возможностей и эффективности применения метода проектов в рамках преподавания дисциплины «Иностранный язык». Суть вопроса заключается, на наш взгляд, в том, что проектное обучение ориентировано, главным образом, на дисциплины с практическим применением результатов проектной деятельности студентов, будь то научно-теоретические положения при работе с магистерской 
диссертацией, или практическое приложение приобретенных знаний и навыков вплоть до технологических стартапов. Поэтому чаще всего проектный метод используется в рамках профильных предметов при обучении студентов старших курсов бакалавриата, специалитета или магистратуры.

Возникает вопрос: «на каком этапе образования и благодаря чему формируются способность мыслить и действовать проектно, умение презентовать и отстаивать свою идею, навыки лидерства и работы в команде» [1c.6]? Возможно ли эффективное использование метода проектов при обучении иностранному языку на начальном этапе обучения в вузе? Мы считаем, что не только возможно, но и необходимо, чтобы студенты уже с первого и второго курса бакалавриата имели представление о проектной деятельности и получили первичные навыки работы над проектом.

Внедрение метода проектного обучения в современные образовательные структуры это хорошо забытое старое. Методика проектов прошла исторический путь от первых попыток применения в начале XX века, через масштабное использование в отечественной педагогике в 20-30 годы на уровне трудовых школ, и в дальнейшем через утрату к середине прошлого века широких позиций данной методики в пользу преимущественного закрепления рецептурного знания в рамках традиционного классно-урочного образования. Возрождение интереса к проектному методу в новом тысячелетии обусловлено несколькими факторами, ключевым из которых является взрывной рост информационных технологий. Широкий доступ к информации требует изменения самой сути образовательного процесса: с одной стороны, обучающиеся включены в творческий поиск и обработку необходимого материала, с другой стороны, преподаватель не является больше единственной активной фигурой образовательного процесса; обучение утрачивает преимущественный монологический характер, все более приобретая статус диалога и полилога. В этом суть как проектного метода, так и возрождения и становления института менторства, когда преподаватель становится наставником. Е. Кулешова дает образное сравнение роли преподавателя с мастером бонсаи, чья задача «где-то отщипывать, где-то добавлять, искривлять и выпрямлять, чтобы получился шедевр. Мастер бонсаи не подменяет собой ни природу, ни само растение - он только подправляет процесс, предвидя результат» [2].

Проектное обучение можно определить как особую форму организации учебного процесса, «направленную на решение студентами практических задач, возникающих в сфере их профессиональной деятельности. Выполняя проекты, обучающиеся осваивают алгоритм инновационной творческой деятельности, учатся самостоятельно ставить цели, находить и анализировать информацию, получать и применять знания по различным отраслям, восполнять пробелы, приобретать опыт решения творческих задач, работать в группе» [3, с. 138]. В отношении к иностранному языку проектная деятельность подразумевает языковую составляющую, фундированную через речевое общение, вплетенное в интеллектуальноэмоциональный контекст другой деятельности [4, с.162]. Специфика преподавания иностранного языка как средства межкультурной коммуникации предполагает использование метода проектов, «который позволяет реализовать наиболее сложную и существенную для методики задачу - создание языковой среды, а на ее основе создание потребности в использовании иностранного языка на практике» [4, с.162]. Исходя из этого, первоочередная и наиболее общая задача при планировании работы над проектом формирование у студентов коммуникативного навыка, поскольку «главным объектом изучения ИЯ является иноязычная речевая деятельность, так как она представляет собой средство межкультурного взаимодействия в целом» [5, с.21]. Введение темы проекта, её обсуждение также способствует развитию иноязычной коммуникативной компетенции учащихся. По-сути, сам проект, его подготовка и реализация является эффективным катализатором развития самостоятельной работы студентов над совершенствованием своих языковых способностей; «они поставлены перед необходимостью самостоятельного выбора аргументов для своего высказывания, использования соответствующих языковых и речевых средств» [4, с.164]. В этом плане проектная деятельность активизирует и актуализирует 
лексическую и грамматическую составляющие, поскольку говорение в режиме презентации проекта невозможно без тщательной проработки лексики по теме проекта и без корректной грамматической подачи материала.

Многие исследователи акцентируют внимание на этапах работы над проектом и способах его реализации - от презентации до разработки web-сайта. В целом предлагаемые разными авторами [4, 5, 6] этапы работы над проектом можно определить как подготовительный (постановка проблемы, распределение ролей в группе, сбор информации, первичная работа с лексическим и грамматическим материалом), творческий (активная фаза работы над проектом) и основной (презентация и оценка результата проектной деятельности). Отметим, что на всех этапах работы активная роль принадлежит самим обучающимся, преподаватель осуществляет регулирующую функцию. Подчеркнем и тот факт, что коммуникативная направленность в обучении иностранному языку дает возможность наиболее эффективного использовать игровой элемент в рамках проектной деятельности. Введение темы и проблематики проекта можно представить как игровую ситуацию, при которой языковое поведение максимально приближено к реальному. Студенты в хорошем смысле слова «вынуждены» говорить на иностранном языке на уровне достойном для представления проекта; «иностранный язык используется в максимально приближенных к реальности ситуациях, таким образом, студенты на практике наблюдают необходимость применения иностранного языка» [6]. Проектное обучение оказывается более мотивационно ориентированным по ряду причин. Как было сказано выше, прежде всего это приближенность к реальным условиям использования иностранного языка. Кроме того, осуществление проекта выявляет творческий потенциал студента, его ответственность в командной работе. Не последнюю роль играет самостоятельность в поиске и обработке информации. Приведем пример из практики. На первом курсе бакалавриата студентам предлагается традиционная работа с текстом общеразговорного (обычно страноведческого) характера. Привычная рутинная модель предполагает пассивное знакомство с лексикой, выполнение ряда упражнений на ее закрепление и, как итог, заучивание текста (пересказ). Вряд ли это может вызвать какой-то повышенный интерес у студентов. Но вместо рутиной работы, например, над текстом 'The USA' можно предложить выполнить проект 'Discovering America', предусматривающий работу с картами, поиск исторического материала, ролевые путешествия по стране, ролевые игры (можно «примерить» на себя роль президента и провести предвыборную кампанию), полит.доклады и прочее, с учетом интересов самих обучающихся. Еще большее возрастание интереса, а, следовательно, и эффективности работы с языковым материалом, имеет место в период обучения во втором и третьем семестрах, когда студенты бакалавры начинают осваивать профессиональную лексику и работать со специализированными текстами. Например, в рамках изучения дисциплины «Иностранный язык» в НГАСУ (Сибстрин) студентам архитекторам предлагается представить проект по известному архитектурному сооружению с описанием стиля, проектировочных методов, используемых материалов, архитектурных особенностей. Студенты с удовольствием включаются в поиск необходимой информации, вплоть до представления рисунков, схем, чертежей, а это, в свою очередь, приводит к необходимости использования профессиональной лексики и оформления лексического материала в соответствии со стилистическими, синтаксическими и грамматическими требованиями. Обучающиеся сами приходят к осознанию того факта, что грамматика - это не бесконечная череда непонятных упражнений, а необходимое условие существования текстового сообщения, письменного и устного. И здесь на первый план выходит менторская роль преподавателя как консультанта по сложным вопросам.

В.Г. Павленко, приводит статистические данные, демонстрирующие эффективность применения проектного метода при обучении иностранному языку. Так, например, показатель с низким уровнем обученности студентов уменьшился на 8\%, с высоким уровнем увеличился на 3\%, со средним уровнем увеличился на 5\% [5]. 
Потенциал и эффективность метода проектов очевидны и отвечают вызовам как современного образования, так и современного общества, которому необходим не просто дипломированный работник, но специалист, нацеленный на творческий подход в своей деятельности, умеющий ставить цели, решать задачи, работать в команде.

В отношении преподавания иностранного языка в вузе можно говорить о повышении мотивации, интереса к иностранному языку, осознании необходимости осуществлять речевую деятельность на иностранном языке, в том числе в рамках профессионального общения, что отвечает новым программным требованиям.

1. Проектное обучение. Практика внедрения в университетах. Под ред. Л.А. Евстратовой, Н.В. Исаевой, О.В. Лешукова. Открытый университет Сколково. М., 2018. 152 с.

2. Кулешова Е. 5 мифов о проектном обучении / https://mel.fm/blog/elena-kuleshova/6742-5-mifov-o-proyektnomobuchenii-s-oproverzheniyem-i-razrusheniyem

3. У Унов А.Л., Плехова Ю.О. Проектное обучение в формате Всероссийской школы «Технологии + бизнес» // Проектное обучение. Практика внедрения в университетах. Под ред. Л.А. Евстратовой, Н.В. Исаевой, О.В. Лешукова. Открытый университет Сколково. М., 2018. С. 138-149.

4. Розова Е.О. Использование проектной методики при обучении иностранному языку // Lingua mobilis. № 1 (34), 2012. C. 162-167.

5. Павленко В. Г. Использование проектного метода при обучении английскому языку в неязыковом вузе // Концепт. № 11, 2015. С. 21-25.

6. Борзенко, Н. А. Метод проектов как эффективный метод преподавания профессионального иностранного языка в неязыковом вузе // Актуальные задачи педагогики: материалы VI Междунар. науч. конф. (г. Чита, январь 2015 г.). Чита: Издательство Молодой ученый, 2015. С. 161-163.

\section{Михеева Н.В., Клементьева А.М. \\ Программа поликультурного образования «Северное сияние» на 2021-2025 уч. г.г.}

МАОУ «Средняя общеобразовательная школа № 22»

(Россия, Северодвинск)

doi: 10.18411/trnio-01-2022-146

\section{Аннотация}

Данная программа призвана решать такие актуальные задачи нашего времени, как формирование представлений о многообразии культур и их взаимосвязи; осознание важности культурного многообразия для самореализации личности; воспитание позитивного отношения к культурным различиям; развитие умений и навыков взаимодействия носителей разных культур на основе толерантности и взаимопонимания.

Программа поликультурного образования является дополнением и продолжением реализуемой в школе программы духовно-нравственного воспитания обучающихся «Я гражданин своего города, своей страны», так как в связи со становлением и развитием в России гражданского общества все большее значение приобретает задача приобщения школьников к национально-культурным традициям русского народа, других народов России, а также формирования уважительного отношения к этнокультурному наследию зарубежных стран.

Ключевые слова: программа, поликультурное образование, начальные классы, самореализация личности, многообразие культур, традиции русского народа.

\section{Abstract}

This program is designed to solve such urgent problems of our time as the formation of ideas about the diversity of cultures and their interrelationships; awareness of the importance of cultural diversity for the self-realization of the individual; education of a positive attitude to cultural differences; development of skills and skills of interaction of carriers of different cultures based on tolerance and mutual understanding. 